\title{
Empirical evaluation of spatial and non-spatial European-scale multimedia fate models: results and implications for chemical risk assessment $\dagger \ddagger$
}

\author{
James M. Armitage, ${ }^{a}$ Ian T. Cousins, ${ }^{* a}$ Mara Hauck, ${ }^{b}$ Jasper V. Harbers ${ }^{b}$ and \\ Mark A. J. Huijbregts ${ }^{b}$
}

Received 17th January 2007, Accepted 16th March 2007

First published as an Advance Article on the web 17th April 2007

DOI: $10.1039 / \mathbf{b} 700680 b$

\begin{abstract}
Multimedia environmental fate models are commonly-applied tools for assessing the fate and distribution of contaminants in the environment. Owing to the large number of chemicals in use and the paucity of monitoring data, such models are often adopted as part of decision-support systems for chemical risk assessment. The purpose of this study was to evaluate the performance of three multimedia environmental fate models (spatially- and non-spatially-explicit) at a European scale. The assessment was conducted for four polycyclic aromatic hydrocarbons (PAHs) and hexachlorobenzene (HCB) and compared predicted and median observed concentrations using monitoring data collected for air, water, sediments and soils. Model performance in the air compartment was reasonable for all models included in the evaluation exercise as predicted concentrations were typically within a factor of 3 of the median observed concentrations. Furthermore, there was good correspondence between predictions and observations in regions that had elevated median observed concentrations for both spatiallyexplicit models. On the other hand, all three models consistently underestimated median observed concentrations in sediment and soil by 1-3 orders of magnitude. Although regions with elevated median observed concentrations in these environmental media were broadly identified by the spatially-explicit models, the magnitude of the discrepancy between predicted and median observed concentrations is of concern in the context of chemical risk assessment. These results were discussed in terms of factors influencing model performance such as the steady-state assumption, inaccuracies in emission estimates and the representativeness of monitoring data.
\end{abstract}

\section{Introduction}

Multimedia environmental fate models are commonly applied to predict the fate of chemicals in the environment for both evaluative (e.g. ranking exercises, model or process description comparisons) and realistic purposes (e.g. comparison to monitoring data). These fate models are capable of representing a variety of scales (i.e. local, regional, continental, global) and incorporate different model structures, process descriptions and levels of complexity depending on the situation, availability of required input data and needs of the end users.

\footnotetext{
${ }^{a}$ Department of Applied Environmental Science (ITM), Stockholm University, 10691 Stockholm, Sweden. E-mail: ian.cousins@itm.su.se; Fax: +468674 7638;Tel: +468164012

${ }^{b}$ Department of Environmental Science, Institute for Wetland and Water Research, Faculty of Science, Radboud University Nijmegen, P.O. Box 9010, 6500GL Nijmegen, The Netherlands

$\dagger$ Presented at Sources, Fate, Behaviour and Effects of Organic Chemicals at the Regional and Global Scale, 24th-26th October 2006, Lancaster, UK.

$\ddagger$ Electronic supplementary information (ESI) available: A figure of geometric mean and median atmospheric concentrations of benzo(a)pyrene at several EMEP sampling sites from 1994-2002, tables summarizing the range of median observed and predicted concentrations generated by the three models and a table listing the input parameters included in the uncertainty analysis along with the assumed variability. See DOI: 10.1039/b700680b
}

Owing to the large number of chemicals in use and the paucity of monitoring data, environmental fate models are often adopted as part of decision-support systems for chemical risk assessment. For example, the European Union System for the Evaluation of Substances (EUSES) was developed to address the need to determine the risk posed to human health and the environment of notified current-use and new substances. ${ }^{1,2}$ This system relies on a regional distribution model based on the SimpleBox platform ${ }^{3,4}$ to generate predicted environmental concentrations (PECs) in environmental compartments (e.g. air, water, sediment, soil) that can then serve as input to a human exposure model. Other examples of similar models include CalTOX ${ }^{5}$ and HAZCHEM. ${ }^{6}$ Although such models allow the rapid and relatively inexpensive assessment of chemical fate in the environment, it is imperative that the model output reflects measured concentrations in the environment and that systematic biases are not present.

In the context of chemical risk assessment conducted at large spatial scales, the potential variability in environmental (i.e. landscape) properties and its influence on model output and reliability is an emerging issue of interest. In a recent evaluation of the EUSES platform using a representative set of compounds, uncertainty in environmental parameters typically contributed more to overall output uncertainty than uncertainty in substance parameters, ${ }^{7,8}$ given the set of input 
parameters considered. In another model exercise using a spatially-resolved multimedia model of the Great Lakes, Luo and Yang ${ }^{9}$ reported that substance parameter uncertainty contributed more to overall output uncertainty than uncertainty in environmental parameters for benzo $[a]$ pyrene whereas the opposite was found for hexachlorobenzene. These studies and others (e.g. Webster et al. $\left.{ }^{10}\right)$ indicate the need to incorporate variability in environmental properties as well as substance properties to improve the quality and reliability of model output, especially for models that represent large geographical regions. This recognition is one factor that has encouraged the development of spatially-explicit models including several at a European scale. Such efforts have been facilitated by the increased availability of spatially-resolved databases for emission estimates along with landscape and climatic parameters. Using this information, these models have the potential to represent some of the spatial (and temporal) variability of the environment of the geographical area under consideration.

Model evaluations of spatially-explicit models have tended to focus on comparisons to non-spatial versions of the same model domain (e.g. Klepper and den Hollander ${ }^{11}$ and Pennington et al. ${ }^{12}$ ) or model intercomparisons between different model platforms using a variety of criteria including overall persistence, long-range transport potential, and chemical ranking as well as individual process-based rate comparisons. ${ }^{13-20}$ While these studies often demonstrate the convergence of model outputs, confidence in the use of these models in a risk assessment context can only be achieved by comparing model-predicted environmental concentrations against actual monitoring data. Unfortunately, comparisons between predicted and measured concentrations have generally been hindered by the lack of spatially-resolved emission estimates and the lack of representative multimedia monitoring data covering the geographical area of interest. Although there are some examples of empirical model evaluation at large scales for both spatially- and non-spatially-explicit models, ${ }^{8,9,21,22}$ there is a lack of this type of research for models at a continental European scale. The few examples in the literature often focus only on the air compartment rather than extending the analysis to other environmental media (e.g. Prevedouros et al $^{23,24}$ ).

The goal of this article was to investigate this issue further by more comprehensively evaluating the performance of three multimedia environmental fate models (spatially- and nonspatially-explicit) at a European scale using monitoring data collected for air, water, sediments and soils across Europe. The findings were then discussed in the context of chemical risk assessment.

\section{Methods}

\section{Selected models}

SimpleBox $3.0,{ }^{4}$ EVn-BETR ${ }^{23,24}$ and IMPACT $2002^{25}$ were selected for this model evaluation exercise because of their availability to the public, ease of use and documented applications in peer-reviewed scientific literature (i.e. transparency). The capability to screen large numbers of chemicals in a relatively short period of time is also an important considera- tion in the context of chemical risk assessment. All three models can accommodate this practical demand by conducting simulations under the assumption of steady-state conditions, which greatly reduces computation time and input data requirements. SimpleBox 3.0 is a nested multimedia fate model that includes a local, regional and continental scale as well as a global scale which represents the northern hemisphere as an arctic, moderate and tropic zone. For this model exercise, the continental-scale component was used as a non-spatially explicit representation of Europe. The other two models represent Europe with different resolutions and geographical coverage. EVn-BETR includes the majority of continental Europe and Scandinavia and divides the model domain based on a $5 \times 5^{\circ}$ grid. The model then generates predicted concentrations in all environmental compartments (e.g. air, freshwater, sediment, soil) in each zone. IMPACT 2002 explicitly includes areas in Western Europe only and divides the model domain into 135 irregular watershed areas (land zones) and 156 separate air zones based on a $2 \times 2.5^{\circ}$ grid. No attempt was made to 'normalize' the models to one another in terms of model structure, parameterization and algorithms as the purpose of the exercise was to compare each model directly with monitoring data rather than against one another. For further details on model structures and parameterization, the reader is referred to the cited references.

\section{Selected chemicals}

The model evaluation exercise was conducted for the following chemicals; benzo $[a]$ pyrene $(\mathrm{BaP})$, benzo $[b]$ fluoranthene $(\mathrm{BbF})$, benzo $[k]$ fluoranthene $(\mathrm{BkF})$, indeno[1,2,3-cd]pyrene (IP) and hexachlorobenzene (HCB). These chemicals were selected primarily due to the availability and geographical coverage of monitoring data in air, freshwater, sediment and soil, the availability of spatially-resolved emission estimates and their toxicological relevance. Key physico-chemical properties for these chemicals are shown in Table 1. These parameter values were based on the SRC Interactive PhysProp Database, ${ }^{26}$ Mackay, ${ }^{27}$ Cousins and Mackay ${ }^{28}$ and Gusev et al. ${ }^{29}$

\section{Emission estimates}

Atmospheric emission estimates for PAHs and HCBs were based on official data submitted to the UN ECE secretariat and available expert estimate $\mathrm{s}^{30-33}$ made available through the EMEP program (http://www.emep.int). More detailed information on the derivation of these emission estimates can be found in MSC-E/CC reports 7/2002 and 3/2003 ${ }^{34,35}$ Emission totals for PAHs were based on 2003 estimates while emission totals for HCB were based on estimates from 1995. The emission estimates, originally projected on a $50 \mathrm{~km} \times 50 \mathrm{~km}$ grid, were aggregated to match the spatial resolution and grid structure for each model using GIS software. This manipulation essentially represents a spatial-averaging of the emissions on an areal basis (i.e. per $\mathrm{km}^{2}$ ) for each model zone. Emissions via alternative modes of entry (e.g. direct or indirect discharge to waterways) have not been included. However, since PAHs are released in industrialized countries mainly as a consequence of combustion and other thermal processes, ${ }^{36}$ the dominance of an atmospheric mode of entry is justifiable. 
Table 1 Summary of key substance parameter inputs ${ }^{a}$ used for model evaluation exercise

\begin{tabular}{|c|c|c|c|c|c|c|}
\hline Parameter & Units & $\mathrm{BaP}$ & $\mathrm{BbF}$ & $\mathrm{BkF}$ & IP & $\mathrm{HCB}$ \\
\hline MM & $\mathrm{g} \mathrm{mol}^{-1}$ & 252.3 & 252.3 & 252.3 & 276.4 & 284.8 \\
\hline MP & ${ }^{\circ} \mathrm{C}$ & 176.5 & 168 & 217 & 163.6 & 231.8 \\
\hline$H$ & $\mathrm{~Pa} \mathrm{~m} \mathrm{~mol}^{-1}$ & $4.60 \times 10^{-2}$ & $6.70 \times 10^{-2}$ & $5.90 \times 10^{-2}$ & $3.53 \times 10^{-2}$ & $1.70 \times 10^{2}$ \\
\hline VAP & $\mathrm{Pa}$ & $7.30 \times 10^{-7}$ & $6.70 \times 10^{-5}$ & $1.30 \times 10^{-7}$ & $1.67 \times 10^{-8}$ & $2.40 \times 10^{-3}$ \\
\hline SOL & $\mathrm{mg} \mathrm{l}^{-1}$ & $1.62 \times 10^{-3}$ & $1.50 \times 10^{-3}$ & $8.00 \times 10^{-4}$ & $1.90 \times 10^{-4}$ & $6.20 \times 10^{-3}$ \\
\hline $\log K_{\mathrm{OW}}$ & - & 6.13 & 5.78 & 6.11 & 6.7 & 5.73 \\
\hline $\mathrm{DEG}_{\mathrm{air}}$ & $\mathrm{h}$ & 170 & 170 & 170 & 170 & 14260 \\
\hline $\mathrm{DEG}_{\mathrm{water}}$ & $\mathrm{h}$ & 1700 & 1700 & 1700 & 1700 & 1700 \\
\hline $\mathrm{DEG}_{\text {soil }}$ & $\mathrm{h}$ & 17000 & 17000 & 17000 & 17000 & 17000 \\
\hline $\mathrm{DEG}_{\text {sed }}$ & $\mathrm{h}$ & 55000 & 55000 & 55000 & 55000 & 55000 \\
\hline Emissions & Metric $\mathrm{t}^{-1}$ & 310 & 340 & 190 & 290 & 25 \\
\hline
\end{tabular}

${ }^{a} \mathrm{MM}=$ molecular mass; $\mathrm{MP}=$ melting point; $H=$ Henry's Law constant; $\mathrm{VAP}=$ vapour pressure; $\mathrm{SOL}=$ aqueous solubility; $K_{\mathrm{OW}}=$ octanol-water partition coefficient; DEG = degradation half-lives in respective media.

Emission estimates compiled by the European Pollutant Emission Register (http://eper.ec.europa.eu/eper) for 2001 also support this assumption for these chemicals (e.g. emissions to air account for $c a .85 \%$ of total emissions for the $\Sigma \mathrm{PAHs}$ ). Aggregated emission totals (metric tonnes $\mathrm{y}^{-1}$ ) for each chemical are shown in Table 1.

\section{Monitoring data}

Monitoring data for PAHs and $\mathrm{HCB}$ were extracted from a European-wide monitoring database compiled by Armitage and Cousins. ${ }^{37}$ In brief, the majority of the monitoring data for PAHs and HCBs in the air compartment were taken from EMEP monitoring sites (http://www.emep.int), which were established as representative background locations across Europe. Measurements from 1994-2003 (time span varies by location) were included in the monitoring data. Freshwater and sediment measurements were based exclusively on the Combined Monitoring-based and Modelling-based Priority Setting database (COMMPS; http://www.europa.eu.int/comm/ environment/water/water-framework/preparation_priority_list. htm) which included samples collected predominantly in 1995-1996. Compilation of this database included a screening process to remove sampling locations that were obviously biased due to proximity to direct sources. Monitoring data for HCB in soils included all European background locations sampled by Meijer et al. ${ }^{38}$ as well as samples collected and analyzed by RECETOX (http://www.recetox.muni.cz) in the Czech Republic (I. Holoubek, personal communication). Measurements of PAHs in soils were taken from several studies available in the literature considered to have sampled at representative background locations ${ }^{39-41}$ as well as the monitoring site in the Czech Republic.

Measured concentrations in air (total, $\mathrm{ng} \mathrm{m}^{-3}$ ), freshwater (total, ng $\mathrm{L}^{-1}$ ), sediment and soil (ng $\mathrm{g}^{-1}$ dry weight) were compiled into spreadsheets specific to each model based on the reported location of the monitoring site and the corresponding grid zone of each model. All monitoring data for PAHs were aggregated because no consistent temporal trends in the available measured air concentrations were apparent over the time span of the observations, ${ }^{42}$ as illustrated in the ESI $\ddagger$ (Fig. S1) for several EMEP monitoring sites. Monitoring data for HCB were also aggregated although there is evidence that suggests ambient air concentrations in some parts of Europe have declined by a factor of two between 1998 and $2004{ }^{43}$ Procedures described by $\mathrm{Helsel}^{44}$ were utilized to compute the minimum, 25th-percentile, median, 75th-percentile and the maximum of the reported values as these methods can handle datasets containing non-detects with multiple detection limits. These techniques are similar to the log-probit approach recommended by Sinha et al. ${ }^{45}$ The overall median and range of all observed concentrations along with the total number of observations in air, freshwater, sediment and soil for each chemical are presented in Table 2. These values were used in the model evaluation of SimpleBox 3.0. Summary statistics were also calculated in all EVn-BETR and IMPACT2002 model zones containing monitoring data. Following the guidelines suggested by Helsel, ${ }^{44}$ this procedure was only applied if there were more than ten data points in the model zone, at least $20 \%$ of which were measurements above the reported detection limits. If these two criteria were not fulfilled, the model zone was not included in the model evaluation exercise for that compartment. Based on these criteria and the monitoring data available, exclusions considering both spatial models occurred predominantly for PAHs in the freshwater compartment (12 of 64 model zones) and HCB in sediment (12 of 130 model zones). After these exclusions, summary statistics of the monitoring data were available for approximately $10-20 \%$ of the grid zones of EVn-BETR and $3-30 \%$ of the grid zones in IMPACT 2002, depending on the environmental media considered. The range of median observed concentrations calculated across the EVn-BETR and IMPACT2002 model zones containing monitoring data are presented in the ESI $\ddagger$ (Table S1).

\section{Indicator of model performance}

To express the performance of each model in a quantitative way, the following measure known as model bias was utilized. ${ }^{46,47}$ The overall model bias (MB) is calculated as:

$$
\mathrm{MB}=10 \frac{\sum_{i}^{n} \log \frac{\operatorname{Predicted}(i)}{\operatorname{Observed}(i)}}{n}
$$

where Predicted $(i)$ is the concentration predicted by the model in compartment $i$, Observed $(i)$ is the median observed concentration in compartment $i$ and $n$ is the number of 
Table 2 Median and ranges of reported concentrations in air, freshwater, sediment and soil ${ }^{a}$

\begin{tabular}{|c|c|c|c|c|c|c|c|c|}
\hline \multirow[b]{2}{*}{ Chemical } & \multicolumn{2}{|l|}{ Air } & \multicolumn{2}{|c|}{ Freshwater } & \multicolumn{2}{|l|}{ Sediment } & \multicolumn{2}{|l|}{ Soil } \\
\hline & $\begin{array}{l}\text { Median/ } \\
\mathrm{ng} \mathrm{m}^{-3}\end{array}$ & $\begin{array}{l}\text { Range/ } \\
\operatorname{ng~m}^{-3}(n)\end{array}$ & $\begin{array}{l}\text { Median/ } \\
\text { ng L }^{-1}\end{array}$ & $\begin{array}{l}\text { Range/ } \\
\operatorname{ng~L}^{-1}(n)\end{array}$ & $\begin{array}{l}\text { Median/ } \\
\text { ng g }^{-1}\end{array}$ & $\begin{array}{l}\text { Range/ } \\
\text { ng g }^{-1}(n)\end{array}$ & $\begin{array}{l}\text { Median/ } \\
\text { ng g }^{-1}\end{array}$ & $\begin{array}{l}\text { Range/ } \\
\operatorname{ng~g}^{-1}(n)\end{array}$ \\
\hline $\mathrm{BaP}$ & 0.053 & $\begin{array}{c}\text { ND-13.8 } \\
(705)\end{array}$ & 3.1 & $\begin{array}{r}\text { ND-10 } \\
(623)\end{array}$ & 400 & $\begin{array}{r}\text { ND-4400 } \\
(1929)\end{array}$ & 10 & $\begin{array}{r}\text { ND_940 } \\
(160)\end{array}$ \\
\hline $\mathrm{BbF}$ & 0.081 & $\begin{array}{c}\text { ND-34.5 } \\
(557)\end{array}$ & 3.6 & $\begin{array}{c}\text { ND-5.6 } \\
(618)\end{array}$ & 480 & $\begin{array}{r}\text { ND }-6400 \\
(1914)\end{array}$ & 12 & $\begin{array}{r}\text { ND }-910 \\
(133)\end{array}$ \\
\hline $\mathrm{BkF}$ & 0.068 & $\begin{array}{l}\text { ND-9.71 } \\
(555)\end{array}$ & 1.6 & $\begin{array}{r}\text { ND-21 } \\
(618)\end{array}$ & 200 & $\begin{array}{r}\text { ND } 4570 \\
(1910)\end{array}$ & 5.9 & $\begin{array}{r}\text { ND }-300 \\
(130)\end{array}$ \\
\hline IP & 0.061 & $\begin{array}{c}\text { ND-20.4 } \\
(633)\end{array}$ & 1.5 & $\begin{array}{r}\text { ND }-430 \\
(705)\end{array}$ & 100 & $\begin{array}{r}\text { ND-12 } 680 \\
(451)\end{array}$ & 6.8 & $\begin{array}{r}\text { ND } 470 \\
(138)\end{array}$ \\
\hline $\mathrm{HCB}$ & 0.054 & $\begin{array}{c}\text { ND-0.3 } \\
(382)\end{array}$ & - & - & 5.6 & $\begin{array}{r}\text { ND } 4960 \\
(2192)\end{array}$ & 0.5 & $\begin{array}{c}\text { ND-9.2 } \\
(178)\end{array}$ \\
\hline
\end{tabular}

${ }^{a}$ The total number of observations $(n)$ is shown beneath the range of reported observations. ND means that the observed value was below the reported detection limit.

comparisons. MB represents the factor by which the predictions tend to under- or over-estimate the observations. For example, a $\mathrm{MB}$ of 5 indicates that the predictions tend to overestimate observations by a factor of 5 . Conversely, a MB of 0.2 indicates that the predictions tend to underestimate observations by a factor of 5 .

\section{Results}

Predicted versus median observed concentrations for SimpleBox 3.0 and the EVn-BETR and IMPACT2002 model zones containing monitoring data for PAHs and HCB in air, freshwater, sediments and soils are presented in Fig. 1. The corresponding MBs of the predictions generated by all models in air, freshwater, sediments and soil for each chemical are presented in Table 3. A comparison of the median and range of predicted concentrations in these compartments across the entire model domain and in zones containing monitoring data for EVn-BETR and IMPACT2002 are presented in the ESI $\ddagger$ (Table S2) along with the predicted concentrations generated by SimpleBox 3.0.

\section{Air compartment}

Model performance in the air compartment was reasonable for all models included in the evaluation exercise. Predicted concentrations of PAHs and HCB generated by SimpleBox 3.0 tended to overestimate the median observed values as shown in Fig. 1(a) but were typically within a factor of 3 with the exception of $\mathrm{BbF}$ (Table 3). Predicted concentrations generated by EVn-BETR and IMPACT2002 showed better agreement with median observed concentrations and were all within a factor of 3 . The predictions generated by IMPACT 2002 tended to systematically overestimate median observed concentrations while predictions generated by EVn-BETR showed no systematic bias and were also typically in better agreement with observations. However, this particular finding may simply be a function of how monitoring data were assigned to the model zones, which differed due to the particular spatial resolution and coverage of each model. The median and range of predicted concentrations for all chemicals across the entire model domains and among zones containing monitoring data were similar for both models [ESI $\ddagger$ (Table S2)], indicating a general convergence of model output in the air compartment. The ability to identify locations with elevated concentrations is an important advantage of adopting spatially-explicit models for chemical risk assessment, particularly given the fact that the range of median observed concentrations calculated for all model zones containing monitoring data varied by up to two orders of magnitude (Table S1).

\section{Freshwater compartment}

Predicted concentrations of PAHs generated by SimpleBox 3.0 and IMPACT2002 tended to underestimate median observed concentrations but were typically within a factor of 3 (Table 3). In general, model zones with elevated median observed concentrations were identified by IMPACT2002 [Fig. 1(b)] further demonstrating the advantage of adopting a spatiallyresolved model in comparison to a non-spatial model. This result is important given the fact that median observed concentrations varied by up to one order of magnitude among model zones containing monitoring data [ESI $\ddagger$ (Table S1)]. Model performance of EVn-BETR was less satisfactory. Predicted concentrations typically underestimated median observed concentrations by 1-2 orders of magnitude and the model did not identify zones with elevated median observed concentrations as consistently as IMPACT2002 [Fig. 1(b)]. These results may indicate that significant improvements in model performance can be gained by adopting a watershed approach in dividing the land compartments compared with the traditional grid approach. The parameterization of the freshwater compartment may also be a contributing factor to the performance of each model. For example, while the total surface area of the freshwater compartments in the three models is similar $\left(1.1 \times 10^{11}\right.$ to $\left.1.3 \times 10^{11} \mathrm{~m}^{2}\right)$, the depth and hence the total volume of the freshwater compartments differ. SimpleBox 3.0 assumes an average depth of $3 \mathrm{~m}$ at the continental scale, EVn-BETR a depth of $20 \mathrm{~m}$ in all model zones, while the depth of the freshwater compartments in IMPACT2002 varies from 0.01 to $167 \mathrm{~m}$ with a weighted average of approximately $18 \mathrm{~m}$ across the entire model 

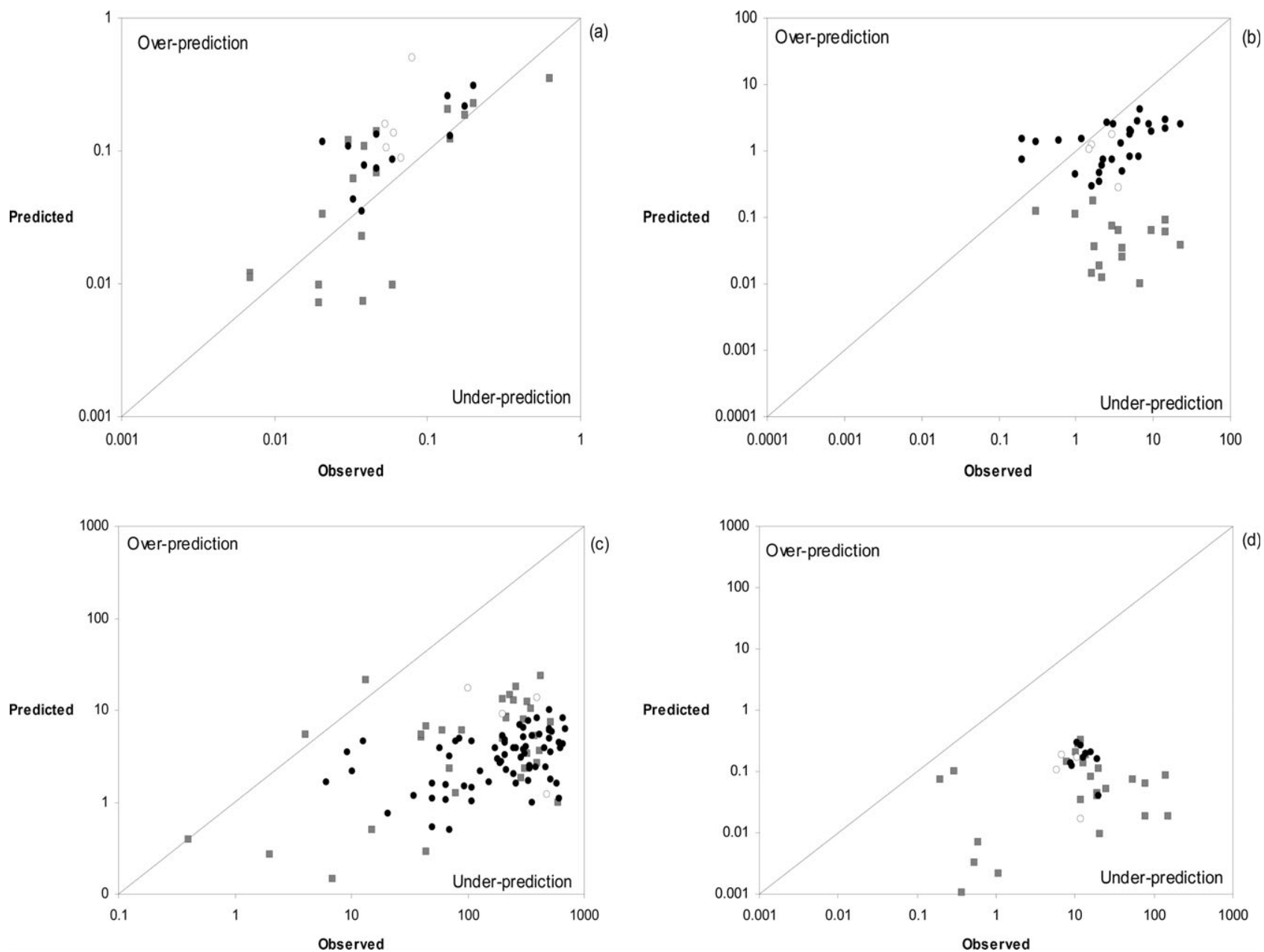

Fig. 1 Predicted versus median observed concentrations for all chemicals in (a) air $/ \mathrm{ng} \mathrm{m}^{-3}$, (b) freshwater $/ \mathrm{ng} \mathrm{L}^{-1}$, (c) sediments $/ \mathrm{ng} \mathrm{g}^{-1}$, and (d) soils/ng g ${ }^{-1}$ for SimpleBox $3.0(\bigcirc)$, EVn-BETR $(\square)$ and IMPACT2002 $(\bullet)$. The solid diagonal line represents unity between predicted and median observed values.

Table 3 Calculated model bias (MB) of predicted concentrations in air, freshwater, sediment and soil compartment for (a) SimpleBox 3.0 (b) EVn-BETR and (c) IMPACT2002

\begin{tabular}{lllll}
\hline Chemical & Air & Freshwater & Sediment & Soil \\
\hline (a) SimpleBox & 3.0 & & & \\
BaP & 3.0 & 0.6 & 0.03 & 0.02 \\
BbF & 6.3 & 0.08 & 0.003 & 0.001 \\
BkF & 1.3 & 0.8 & 0.05 & 0.02 \\
IP & 2.3 & 0.7 & 0.2 & 0.03 \\
HCB & 2.0 & - & 0.003 & $3.1 \times 10^{-4}$ \\
& & & & \\
(b) EVn-BETR & 1.6 & 0.02 & 0.05 & 0.01 \\
BaP & 1.6 & 0.005 & 0.01 & 0.001 \\
BbF & 1.2 & 0.02 & 0.05 & 0.01 \\
BkF & 0.8 & 0.03 & 0.09 & 0.02 \\
IP & 1.3 & - & 0.06 & 0.003 \\
HCB & 0.4 & - & & \\
& & & 0.02 & 0.01 \\
(c) IMPACT2002 & & 0.01 & 0.01 \\
BaP & 2.1 & 0.4 & 0.02 & 0.02 \\
BbF & 2.1 & 0.4 & 0.03 & 0.02 \\
BkF & 1.2 & 0.5 & $2.2 \times 10^{-4}$ & $6.4 \times 10^{-5}$ \\
IP & 1.3 & 0.5 & & \\
HCB & 2.9 & - & &
\end{tabular}

domain. Consequently, the total volume of the EVn-BETR freshwater compartment is nearly an order of magnitude greater than SimpleBox 3.0 and of similar magnitude to IMPACT2002. However, nearly $75 \%$ of the IMPACT 2002 model zones included in the empirical evaluation were parameterized with freshwater compartment depths of less than $1 \mathrm{~m}$, although model zones with depths of up to $85 \mathrm{~m}$ were also included. Thus, the fact that predicted concentrations generated by EVn-BETR for the freshwater compartment tended to be lower than the other models may be partly attributable to the differences in model geometry.

\section{Sediment compartment}

Predicted concentrations of PAHs and HCB generated by all three models typically underestimated median observed concentrations by 1-2 orders of magnitude (Table 3 ). Predicted concentrations generated by SimpleBox 3.0 deviated from median observed concentrations by a factor of approximately 5 for IP, 20-30 for BaP and BkF, and 330 for $\mathrm{BbF}$ and $\mathrm{HCB}$. Predicted concentrations generated by EVn-BETR deviated from median observed concentrations by a factor of approximately 10 for IP, 20 for $\mathrm{BaP}, \mathrm{BkF}$ and $\mathrm{HCB}$ and 100 for $\mathrm{BbF}$. 
Predicted concentrations generated by IMPACT2002 deviated from median observed concentrations by a factor of approximately $40-50$ for IP, BaP and $\mathrm{BkF}, 100$ for $\mathrm{BbF}$ and 4500 for HCB. In this case, the geometry of the sediment compartment is not a concern as the descriptions of the sediment compartments are quite similar between the models in terms of sediment depth (SimpleBox 3.0, $0.03 \mathrm{~m}$; EVn-BETR and IMPACT2002, $0.05 \mathrm{~m}$ ). The larger deviation between predicted concentrations generated by IMPACT2002 and median observed concentrations for HCB is more related to the fact that median observed concentrations tended to be higher based on how monitoring data were assigned to grid zones [ESI $\ddagger$ (Table S1)] while predicted values tended to be lower than EVn-BETR [ESI $\ddagger$ (Table S2)]. It is interesting to note that both spatial models were broadly able to identify model zones with elevated concentrations [Fig. 1)c)] even though the predicted concentrations did not correspond well with observations in absolute terms. This type of information is valuable in a chemical risk assessment context despite the poor model performance in this compartment.

\section{Soil compartment}

Predicted concentrations of PAHs and HCB generated by all three models also typically underestimated median observed concentrations (Table 3). In this case, the range of median observed concentrations calculated for grid zones in both models were similar [ESI centrations included in the model evaluation for IMPACT2002 were higher than predicted concentrations included for EVn-BETR with the exception of HCB [ESI $\ddagger$ (Table S2)]. As in the sediment compartment, model zones with elevated median observed concentrations were broadly identified by EVn-BETR and IMPACT 2002 in relative terms. Predicted concentrations generated by SimpleBox 3.0 deviated from median observed concentrations by a factor of approximately $40-80$ for IP, BaP and BkF, 1000 for BbF and 3000 for HCB. Predicted concentrations generated by EVn-BETR deviated from median observed concentrations by a factor of approximately 50 for $\mathrm{IP}, 100$ for $\mathrm{BaP}$ and $\mathrm{BkF}, 1000$ for $\mathrm{BbF}$ and 300 for HCB. Predicted concentrations generated by IMPACT2002 deviated from median observed concentrations by a factor of approximately $50-100$ for the PAHs and over four orders of magnitude for HCB. The differences in model performance cannot be attributed to model geometry as the depth values of the surface soil layer are nearly identical for all three models (SimpleBox 3.0, $0.09 \mathrm{~m}$; EVn-BETR and IMPACT2002, $0.1 \mathrm{~m}$ ). However, as the majority of soil samples represent the average concentration in the top $5 \mathrm{~cm}$ of soil, a potential bias may be introduced as concentrations in soil are expected to decline exponentially with depth. ${ }^{48-50}$ While incorporating algorithms to account for this factor is justifiable on theoretical and empirical grounds, it is not expected to account for the magnitude of the discrepancies found in this empirical evaluation particularly because a modified version of SimpleBox 3.0 including such algorithms did not produce average soil concentrations that deviated substantially from the unmodified version in an evaluative exercise. $^{49}$

\section{Discussion}

Model performance in the air compartment was reasonable for all models whereas both the non-spatial and spatially-resolved models consistently underestimated the median observed concentrations of PAHs and HCB in sediments and soil. Predicted concentrations also tended to underestimate median observed concentrations in freshwater although the discrepancy varied by model. These results are problematic in the context of both human and ecological risk assessment because many exposure pathways, with the exception of human occupational exposure, are described using algorithms that ultimately relate concentrations in organisms to ambient concentrations primarily in freshwater (e.g. bioconcentration and bioaccumulation factors), sediment or soil (e.g. biota sediment/soil accumulation factors), rather than air. One important exception in the context of human exposure is the transfer of contaminants from air-grass-cows. ${ }^{51}$ Model bias in predicted plant concentrations cannot be assessed in this study because the vegetation compartment was not included in the model evaluation exercise. However, assuming equilibrium partitioning between concentrations in the atmosphere and plants may be a reasonable assumption for certain chemical classes ${ }^{51}$ which suggests that human exposure via this pathway can be adequately described, given the good agreement between measured and predicted air concentrations.

To investigate whether or not the results of this model evaluation exercise were atypical, a literature survey of similar model evaluation exercises at various spatial scales and resolutions was conducted. From this literature survey, it can be concluded that the results of this model evaluation exercise are in general agreement with other studies. For example, the results for polychlorinated dibenzodioxins (PCDDs) reported by Berding, ${ }^{7} \mathrm{BaP}$ and $\mathrm{HCB}$ reported by Luo and Yang, ${ }^{9}$ naphthalene and 1,4-dichlorobenzene (1,4-DCB) reported by Jager, ${ }^{21}$ polybrominated diphenyl ethers (PBDEs) reported by Prevedouros et al. ${ }^{24}$ and benzene and chlorobenzenes reported by MacLeod and Mackay ${ }^{52}$ are similar to the results for PAHs and HCB in this study, i.e. the model performance was best for predictions in the air compartment (within an order of magnitude) and least reliable in the sediment and soil compartments where substantial under-predictions were noted. Sweetman et al. ${ }^{53}$ also reported significant deviations between predicted and observed concentrations of PCBs in sediments and soils in the United Kingdom in a dynamic long-term simulation. The results of this model evaluation exercise are also similar to the results of the model evaluation of MSCE-POP, ${ }^{36}$ a non-steady-state 3D Eulerian fate model with a spatial resolution of $50 \times 50 \mathrm{~km}$. Air concentrations generated by this model were often within a factor of two of the observed concentrations for the chemicals considered [e.g. polychlorinated biphenyls (PCBs), polychlorinated dibenzo-dioxins/-furans (PCDD/Fs), PAHs] while predicted soil concentrations underestimated the reported monitoring data by 1-2 orders of magnitude. Given the findings of the model evaluation and literature survey, a discussion of potential sources of model bias is warranted and includes issues external to the model (i.e. the monitoring data) 
as well as internal to the model application such as the emission estimates and the steady-state assumption. The results from a preliminary model sensitivity analysis are also discussed.

\section{Quality and representativeness of monitoring data}

The model evaluation exercise was conducted assuming that the monitoring data were not systematically biased due to analytical error and were also representative of background conditions in each zone. While monitoring data quality cannot be verified, to the best of our knowledge, all monitoring data were collected from locations distant from point sources. However, it is not possible to definitively prove that the observed data are truly representative of conditions in Europe, particularly because sampling density was low in comparison to the spatial scale of the models. In addition, monitoring data were often collected at different locations (and times) within the assigned model zones. Therefore, confidence in the aggregated monitoring data could be improved if concentration ratios (e.g. $\left.C_{\mathrm{AIR}} / C_{\mathrm{WATER}} ; C_{\mathrm{AIR}} / C_{\mathrm{SOIL}}\right)$ of the median observed concentrations in a series of model zones and measurements collected simultaneously in all environmental matrices (i.e. air, water, soil, sediments) at the same location were shown to be similar. This exercise was not undertaken due to the lack of data from integrated monitoring sites.

The best correspondence between observations and model predictions was found for the air compartment in all cases. This may be related to the comparatively fast rate of mixing which can occur in the atmosphere compared with other less mobile environmental media. For example, measured sediment concentrations within the same square meter were found to vary by a factor of $10-100^{54}$ and it is unclear whether or not this 'within site' variability is captured by the monitoring data used in this exercise. Finally, though the model evaluation was conducted using monitoring data covering a reasonable geographical area, confidence in the results would be increased if more data were readily available at more locations across Europe. As such, there is a need for an expanded network of integrated monitoring sites across Europe as well as a centralized European database where monitoring data could be compiled and made publicly available in standardized formats.

\section{Inaccuracies in current emission estimates}

Breivik et al. ${ }^{55}$ recently reviewed atmospheric emission estimates of persistent organic pollutants (POPs) in Europe and noted that two different source inventories of PAHs (Berdowski et $_{\mathrm{al}}{ }^{31}$ and the EMEP emission database) differed in terms of emission totals for many individual countries in the range of one order of magnitude or greater. Substantial differences in the contribution to emission totals among source category were also noted. However, the authors could not conclusively determine which database was more reliable. Consequently, inaccuracies in the emission totals, assumed mode of entry and spatial distribution of the substances in this model exercise may contribute significantly to the discrepancies between predicted and median observed concentrations.

In terms of the model evaluation exercise, however, since the models constitute linear systems, there is a proportional relationship between emission levels and predicted concentra- tions. This fact implies that the effect of changing the absolute emission totals on predicted concentrations will be related to the change in the emission totals themselves (given the same spatial distribution), i.e. increasing total emissions by a factor of 5 corresponds to the same increase in predicted concentrations, and the ratio of concentrations between environmental media will not change (given the same mode of entry). As stated earlier, the model simulations assumed that the mode of entry of the emissions was entirely to the air compartment for PAHs and HCB and it is possible that the omission of direct discharges to freshwater is contributing to the discrepancy between predicted and observed median concentrations in both freshwater and sediments. However, emissions from wastewater treatment plants and other sources to freshwater will not exert a significant influence on predicted concentrations in freshwater or sediments as long as they are minor relative to atmospheric sources, which seems to be a reasonable assumption on a continental European scale for both PAHs and HCB. Furthermore, the inclusion of these emissions would not significantly impact predicted soil concentrations due to the large volume and sorptive capacity of soil in the model environment. Therefore, inaccuracies in the mode of entry are unlikely to be a significant source of model bias for this model evaluation. The possibility that inaccuracies in the spatial distribution of the atmospheric emission estimates are contributing to model bias is more difficult to assess since no alternative emission estimates at similar spatial resolution were available.

\section{Historic versus current emission estimates}

If emission levels for all substances considered in the model evaluation were higher in the past, steady-state simulations using current emission levels can potentially introduce model bias leading to underestimation of contaminant levels in the environment. Any potential bias will be most acute for environmental compartments with limited removal rates via advection (e.g. soil, sediment) unless degradation rates are high. ${ }^{27}$ Total emission estimates of PAHs at the European level were reportedly 2-4 times higher in 1970 while emissions of $\mathrm{HCB}$ were approximately 10 times higher, respectively for the same period in comparison with the current emission estimates used in this study. ${ }^{56}$ Given the proportional relationship between emission levels and predicted concentrations for steady-state simulations, the maximum bias introduced to non-spatial model predictions is therefore basically the same as the difference in emission levels, i.e. ca. 2-4 for PAHs, and 10 for $\mathrm{HCB}$, respectively, and the ratio between predicted concentrations in the various environmental compartments will not change. Discrepancies between historic and current emission estimates varied across individual countries, implying that the introduced bias can be different in terms of magnitude and direction for the corresponding regions in spatially-explicit models. While a spatially-resolved dynamic (i.e. non-steadystate) model such as MSCE-POP can accommodate regional differences in historic emission estimates, the similar performance of these types of models in the sediment and soil compartments suggests that other factors need to be considered. 


\section{Time-averaged environmental parameters}

Although some spatial variability in environmental parameters can be accounted for by spatially-resolved fate models, the steady-state versions of the models included in the exercise use time-averaged parameter values, meaning that temporal variability is not explicitly represented. In an evaluative model exercise, $\mathrm{Lammel}^{57}$ reported that short-term or seasonal variations in temperature, rainfall and other climatic conditions resulted in a model output that differed from predictions generated using time-averaged values for the POPs and pesticides evaluated. However, the discrepancies between predicted concentrations in bulk compartments of the models (e.g. air, soil) related to the incorporation of temporal variation of environmental parameters exhibited compensatory behaviour (i.e. cancellation of bias) when all environmental parameters considered were varied simultaneously. As a result, the magnitude of the discrepancies between the time-averaged and temporally-resolved models do not appear to be large enough to account for the discrepancies observed in this model evaluation exercise, although this issue requires further investigation.

\section{Enhanced sorption to organic carbon}

The influence of black carbon must also be considered, particularly for PAHs. Although it is well established that the presence of black carbon leads to enhanced sorption of planar compounds, ${ }^{58-60}$ the influence on predicted model concentrations in soils and sediments may be limited for the highmolecular-weight PAHs included in this study. This is because the predicted behaviour of these PAHs is already strongly dominated by sorption to solids (due to the high $\log K_{\mathrm{OC}}$, the organic carbon-water partition coefficient) and thus the proportional change associated with incorporating enhanced sorption to black carbon may be limited. However, incorporating algorithms to include sorption to black carbon can have a more pronounced effect on estimated dissolved concentrations in the water column and pore-water. ${ }^{60}$ Degradation rates in soils and sediments may therefore be overestimated because the fraction of contaminant available to be degraded (i.e. the dissolved fraction) may also be overestimated, resulting in under-prediction of the total concentration. The effect of enhanced sorption is also important in the context of chemical risk assessment because exposure models typically relate concentrations in biota to the dissolved concentration only.

\section{Preliminary model sensitivity analysis (EVn-BETR)}

An additional way to investigate the behaviour of multimedia models is to conduct a model sensitivity and uncertainty analysis. MacLeod et al. ${ }^{61}$ described the theoretical background and assumptions inherent to an analytical approach for conducting a preliminary assessment of uncertainty in multimedia fate models which includes sensitivity analysis, analysis of propagation of variance and estimation of the contribution of individual input parameter uncertainties to the overall output parameter uncertainty. The approach relies on the assumption that variability in all input parameters under consideration can be described by a log-normal distribution. While this assumption may not strictly be true, it is still reasonable in most cases. ${ }^{62} \mathrm{~A}$ preliminary model sensitivity analysis was conducted for predicted concentrations of all chemicals using EVn-BETR because this model platform incorporates routines to perform the analysis. The variance in input parameters was represented by a confidence factor (CF), which represents the factor by which $95 \%$ of the parameter values are expected to deviate from the default (median) value $(\mu)$. The parameters included in the analysis and the corresponding CFs are presented in the ESI $\ddagger$ (Table S3). The interpretation of the results focuses only on model sensitivities since a complete discussion of the results of the analysis is beyond the scope of the current study.

As expected, predicted concentrations in all compartments were highly sensitive to direct emissions. Excluding direct emissions, predicted concentrations of PAHs and $\mathrm{HCB}$ in the air compartment were primarily sensitive to parameters related to removal processes such as degradation (half-life), advection, and deposition (rain scavenging efficiency, aerosol deposition rate and rainfall). This result indicates that parameters related to feedback from other compartments (i.e. air-surface exchange) have little impact on predicted concentrations in the air compartment for chemicals emitted primarily to the atmosphere.

Predicted concentrations in the freshwater, sediment and soil compartments for all chemicals were sensitive to parameters related to depositional processes, removal processes and inter-compartmental exchange. In particular, predicted concentrations of PAHs and HCB in all three compartments were highly sensitive to rainfall and rain scavenging efficiency (deposition) and degradation half-life (removal) in the respective compartments and also in the air compartment to a lesser degree. Additionally, predicted concentrations in freshwater and sediment were sensitive to parameters related to soil runoff (i.e. erosion), indicating the potential importance of this pathway in transferring contaminants from terrestrial to aquatic systems. Predicted concentrations of PAHs in soils and sediments were not highly sensitive to the octanol-water partition coefficient (and hence $K_{\mathrm{OC}}$ ), which suggests that incorporating enhanced sorption to black carbon may not dramatically improve model performance in the soil and sediment compartments for these chemicals. However, this particular issue needs to be more comprehensively investigated. To explore the influence of degradation half-lives on the model output in sediments and soils, a series of model simulations was conducted for BaP using EVn-BETR assuming default half-lives in air and freshwater and simultaneously increasing the degradation half-lives in sediments and soils by a factor of $5,10,100$ and then to a negligible value $\left(t_{1 / 2}=1 \times\right.$ $\left.10^{11} \mathrm{~h}\right)$. These preliminary results suggest that increasing degradation half-lives in sediments by a factor of 10-100 (i.e. $t_{1 / 2}=60-600$ years) and in soils by a factor of 100 or greater (i.e. $t_{1 / 2}=200+$ years) is required to yield predicted concentrations in reasonable agreement with median observed values.

Overall, the results of the model sensitivity analysis reaffirm the need for accurate emission estimates as well as the importance of determining realistic degradation half-lives. Realistic descriptions of air-surface exchange processes are also critical, in particular for chemicals that are primarily emitted to the atmosphere. In terms of the model evaluation exercise, given the fact that predicted concentrations in the air 
compartment for PAHs and HCB were reasonable whereas the corresponding concentrations in the surface compartments were underestimated, it is possible that depositional processes are less problematic than removal processes (e.g. degradation). A large-scale campaign to measure seasonal deposition fluxes and to compare with model predictions could provide additional insights into this issue. Furthermore, a more comprehensive sensitivity and uncertainty analysis is required to investigate the influence of individual parameters on the various process descriptions included in the models.

\section{Conclusions}

The findings of this study suggest that current multimedia fate models underestimate median observed concentrations of PAHs and HCB in sediments and soils by 1-3 orders of magnitude. Substances with similar physico-chemical properties and emission patterns may also be subject to this bias, as indicated by the survey of model evaluation exercises conducted for this study. According to the EU protocols for ecological risk assessment, ${ }^{63}$ the potential risk to organisms in the environment is assessed by comparing the predicted environmental concentrations (PECs) with the predicted no effect concentration (PNEC). PNECs are typically derived from laboratory toxicity tests through the use of assessment factors (AFs), which can vary from a factor of 10 to 1000 . Although the magnitude of the AFs suggests a significant degree of conservatism, the purpose of the AFs is to account for uncertainties related to extrapolation from laboratory toxicity test data for a limited number of species in the derivation of a threshold concentration protective of the entire biosphere. ${ }^{63,64}$ Potential bias in the PEC is not explicitly considered by these AFs. Therefore, although the good agreement between predicted and observed concentrations in the air is encouraging, exposure assessments that rely on the output of similar models may still underestimate the potential risk associated with chemicals that enter the biosphere primarily via uptake from sediments and soils (assuming that the bioavailability of the compounds is accurately predicted by the exposure model). While the steady-state assumption may contribute to the observed bias, the fact that similar patterns were reported for non-steady-state models ${ }^{9,36,53}$ suggests that other factors are more important. This conclusion is highly relevant in the context of chemical risk assessment because the use of non-steady models to perform screening level evaluations for thousands of chemicals would be far more intensive in terms of data requirements, computational effort and costs.

Investigating the apparent discrepancy between monitoring data and model predictions will require a concerted effort as there is a wide range of factors potentially contributing to the apparent discrepancy. The model sensitivity analysis suggests that the methods of characterizing advective losses and exchange processes between the atmosphere and surface compartments may require more detailed consideration and parameterization in multimedia fate models. Further experimental work into degradation rates under realistic environmental conditions is also warranted. Because this investigation focused on chemicals with similar environmental fate profiles (e.g. primarily emitted to the atmosphere; high affinity for organic matter), there is a clear need to conduct similar investigations for substances with different physico-chemical properties and emission patterns (e.g. water-soluble biocides, pesticides) in order to determine if model performance is similar for chemicals exhibiting different modes of entry and chemical fate. To facilitate such efforts, the development of large-scale integrated monitoring campaigns across Europe, including measurements of deposition rates, is essential along with centralized data reporting and dissemination. These activities will support more comprehensive empirical model evaluations and allow further analysis of the implications for chemical risk assessment to be made.

\section{Acknowledgements}

This work was supported by European Commission FP6 Contracts No. 003956 (NOMIRACLE). Dennis Helsel and Steve Saiz are acknowledged for providing assistance related to calculations of summary statistics for censored datasets with multiple detection limits. Costas Prevedouros, Matt MacLeod, David Pennington, Manuele Margni and Ralph Rosenbaum are also acknowledged for providing information about the models selected for this evaluation exercise.

\section{References}

1 T. G. Vermeire, D. T. Jager, B. Bussian, J. Devillers, K. den Haan, B. Hansen, I. Lundberg, H. Niessen, S. Robertson, H. Tyle and P. T. J. van der Zandt, Chemosphere, 1997, 34, 1823-1836.

2 L. Attias, P. Boccardi, G. Boeije, D. Brooke, J. De Bruijn, M. Comber, B. Dolan, S. Fischer, G. Heinemeyer, V. Koch, J. Lijzen, B. Müller, R. Murray-Smith, M. Rikken, J. Tadeo and T. Vermeire, Chemosphere, 2005, 59, 473-486.

3 L. J. Brandes, H. den Hollander and D. van de Meent, SimpleBox 2.0: a nested multimedia fate model for evaluating the environmental fate of chemicals, RIVM Report no. 719101029, National Institute of Public Health and the Environment, Bilthoven, The Netherlands, 1996.

4 H. den Hollander, J. C. H. Van Eijkeren and D. van de Meent, SimpleBox3.0: Multimedia Mass Balance Model for Evaluating the Fate of Chemicals in the Environment, RIVM Report no. 601200003, National Institute of Public Health and the Environment, Bilthoven, The Netherlands, 2004.

5 T. E. McKone, CalTOX, a multi-media total-exposure mode for hazardous waste sites. Part II: The dynamic multi-media transport and transformation model, Report prepared for the State of California, Department Toxic Substances Control by the Lawrence Livermore National Laboratory, No. UCRL-CR-111456PtII, Livermore, CA, USA, 1993.

6 European Centre for Ecotoxicology and Toxicology of Chemicals, HAZCHEM: A mathematical model for use in risk assessment of substances, Special Report No. 8, ECETOC, Brussels, Belgium, 1994.

7 V. Berding, Validation of a Regional Distribution Model in Environmental Risk Assessment of Substances, Doctoral Thesis, Institute of Environmental Systems Research, Department of Mathematics and Computer Science, University of Osnabrück, Germany, 2000.

8 M. Matthies, V. Berding and A. Beyer, Environ. Toxicol. Chem., 2004, 23, 2494-2502.

9 Y. Luo and X. Yang, Chemosphere, 2007, 66, 1396-1407.

10 E. Webster, D. Mackay, A. Di Guardo, D. Kane and D. Woodfine, Chemosphere, 2004, 55, 1361-1376.

11 O. Klepper and H. den Hollander, Ecol. Modeling, 1999, 116, $183-202$.

12 D. W. Pennington, M. Margni, C. Amman and O. Jolliet, Environ. Sci. Technol., 2005, 39, 1119-1128.

13 F. Wania and D. Mackay, A comparison of overall persistence values and atmospheric travel distances calculated by various 
multi-media fate models, WECC Report No. 9461/9462, Wania Environmental Chemists Corp., 2000.

14 D. H. Bennett, M. Scheringer, T. E. McKone and K. Hungerbühler, Environ. Sci. Technol., 2001, 35, 1181-1189.

15 A. Beyer, M. Scheringer, C. Schulze and M. Matthies, Environ. Toxicol. Chem., 2001, 20, 922-927.

16 K. Fenner, M. Scheringer and K. Hungerbühler, Environ. Pollut., 2004, 128, 189-204.

17 F. Wania and C. B. Dugani, Environ. Toxicol. Chem., 2003, 22, 1252-1261.

18 M. Stroebe, M. Scheringer, H. Held and K. Hungerbühler, Sci. Total Environ., 2004, 321, 1-20.

19 V. Shatalov et al., POP Model Intercomparison Study, Stage I. Comparison of descriptions of main processes determining POP behaviour in various environmental compartments, EMEP/MSC-E Technical Report 1/2004, 2004.

20 K. J. Hansen, K. Prevedouros, A. J. Sweetman, K. C. Jones and J. H. Christensen, Atmos. Environ., 2006, 40, 2089-2104.

21 T. Jager, Evaluation of EUSES: Inventory of experiences and validation activities, RIVM report 679102048, National Institute of Public Health and the Environment, Bilthoven, The Netherlands, 1998.

22 K. Kawamoto, M. MacLeod and D. Mackay, Chemosphere, 2001, 44, 599-612.

23 K. Prevedouros, M. MacLeod, K. C. Jones and A. J. Sweetman, Environ. Pollut., 2004, 128, 251-261.

24 K. Prevedouros, K. C. Jones and A. J. Sweetman, Environ. Sci. Technol., 2004, 38, 5993-6001.

25 M. Margni, D. W. Pennington, C. Amman and O. Jolliet, Environ. Pollut., 2004, 128, 263-277.

26 Syracuse Research Corporation (SRC), Interactive PhysProp Database, http://www.syrres.com/esc/physdemo.htm.

27 D. Mackay, Multimedia Environmental Models: The Fugacity Approach, Lewis Publishers, Boca Raton, 2nd edn, 2001.

28 I. T. Cousins and D. Mackay, Chemosphere, 2001, 44, 643-654.

29 A. Gusev, E. Mantseva, V. Shatalov and B. Strukov, Regional multicompartment model MSCE-POP, MSC-E Technical Report 5/2005, 2005.

30 A. Baart, J. Berdowski, J. van Jaarsveld and K. Wulffraat, Calculation of atmospheric deposition of contaminants on the North Sea, TNO-MEP-R 95/138, Delft, The Netherlands, 1995.

31 J. J. M. Berdowski, J. Baas, J. P. J. Bloos, A. J. H. Visschedijk and P. Y. J. Zandveld, 'The European emission inventory of heavy metals and persistent organic pollutants,' in Umweltforschungsplan des Bundeministers für Umwelt, Naturschutz und Reaktorsicherheit, Luftreinhaltung, Forchungsbericht 10402 672/03, TNO, Apeldoorn, The Netherlands, 1997.

32 J. M. Pacyna et al., Final report for Project POPCYCLING-Baltic, EU DGXII, Environment and Climate Program ENV4-CT960214, NILU, Kjeller, Norway, 1999.

33 V. Tsibulsky, S. Sokolovsky, S. Dutchak and V. Shatalov, MSC-E contribution to the HM and POP emission inventories, EMEP/ MSC-E Technical Note 7/2001, 2001.

34 V. Shatalov, A. Malanichev and N. Vulykh, Assessment of POP transport and accumulation in the environment, MSC-E Technical Report 7/2002, 2002.

35 V. Shatalov, S. Dutchak, M. Fedyunin, E. Mantseva, B. Strukov, M. Varygina, N. Vulykh, N. W. Aas and S. Manø, Persistent Organic Pollutants in the environment, MSC-E/CCC Status Report 3/2003, 2003.

36 V. Shatalov, A. Gusev, S. Dutchak, I. Holoubek, E. Mantseva, O. Rozovskaya, A. J. Sweetman, B. Strukov and N. Vulykh,
Modelling of POP contamination in European region: Evaluation of the model performance, EMEP/MSC-E Technical Report 7/ 2005, 2005.

37 J. M. Armitage and I. T. Cousins, M.2.4.2 European-wide field data report about selected reference compounds, EU Project 003956: NOMIRACLE, 2005.

38 S. N. Meijer, W. A. Ockenden, A. Sweetman, K. Breivik, J. O. Grimalt and K. C. Jones, Environ. Sci. Technol., 2003, 37, 667-672.

39 E. Aamot, E. Steinnes and R. Schmid, Environ. Pollut., 1996, 92, 275-280.

40 Z. M. Migaszewski, A. Galuszka and P. Paslawski, Environ. Int., 2002, 28, 303-313.

41 T. D. Bucheli, F. Blum, A. Desaules and Ö. Gustafsson, Chemosphere, 2004, 56, 1061-1076.

42 K. Prevedouros, E. Brorström-Lundén, C. J. Halsall, K. C. Jones, R. G. M. Lee and A. J. Sweetman, Environ. Pollut., 2004, 128, $17-27$.

43 R. Gioia, E. Steinnes, G. O. Thomas, S. N. Meijer and K. C. Jones, J. Environ. Monit., 2006, 8, 700-710.

44 D. Helsel, Nondetects and Data Analysis: Statistics for Censored Environmental Data, John Wiley \& Sons, Inc., Hoboken, New Jersey, 2005.

45 P. Sinha, M. B. Lambert and V. L. Trumbull, Environ. Toxicol. Chem., 2006, 25, 2533-2540.

46 F. A. P. C. Gobas, J. P. Pasternak, K. Lien and R. K. Duncan, Environ. Sci. Technol., 1998, 32, 2442-2449.

47 J. A. Arnot and F. A. P. C. Gobas, Environ. Toxicol. Chem., 2004, 23, 2343-2355.

48 T. E. McKone and D. H. Bennett, Environ. Sci. Technol., 2003, 35, $142-148$.

49 A. Hollander, L. Hessels, P. de Voogt and D. van de Meent, SAR QSAR Environ. Res., 2004, 15, 457-468.

50 A. Hollander, I. Baijens, A. Ragas, M. Huijbregts and D. van de Meent, Environ. Pollut., 2007, DOI: 10.1016/j.envpol.2006.09.018.

51 M. S. McLachlan, Environ. Sci. Technol., 1996, 30, 252-259.

52 M. MacLeod and D. Mackay, Chemosphere, 1999, 38, 1777-1796.

53 A. J. Sweetman, I. T. Cousins, R. Seth, K. C. Jones and D. Mackay, Environ. Toxicol. Chem., 2002, 21, 930-940.

54 European Centre for Ecotoxicology and Toxicology of Chemicals, Estimating environmental concentrations of chemicals using fate and exposure models, Technical Report No. 50, ECETOC, Brussels, Belgium, 1992.

55 K. Breivik, V. Vestreng, O. Rozovskaya and J. M. Pacyna, Environ. Sci. Pollut., 2006, 9, 663-674.

56 O. Rozovskaya, S. Dutchak and E. Mantseva, Review of available POP emissions data, EMEP MSC-E Information Note 11/2004, 2004.

57 G. Lammel, Environ. Pollut., 2004, 128, 291-302.

58 Ö. Gustafsson, F. Haghseta, C. Chan, J. MacFarlane and P. M. Gschwend, Environ. Sci. Technol., 1997, 31, 203-209.

59 K. Naes, J. Axelman, C. Näf and D. Broman, Environ. Sci. Technol., 1998, 32, 1786-1792.

60 G. Cornelissen, Ö. Gustafsson, T. D. Bucheli, M. T. O. Jonker, A. A. Koelmans and P. C. M. van Noort, Environ. Sci. Technol., 2005, 39, 6881-6895.

61 M. MacLeod, A. J. Fraser and D. Mackay, Environ. Toxicol. Chem., 2002, 21, 700-709.

62 W. Slob, Risk Anal., 1994, 14, 571-576.

63 European Chemicals Bureau, Technical guidance document on risk assessment, EUR $20418 \mathrm{EN} / 2,2003$.

64 P. M. Chapman, A. Fairbrother and D. Brown, Environ. Toxicol. Chem., 1998, 17, 99-108. 